\title{
Effect of Temperature on Creep behavior of Poly(vinyl chloride) Loaded with Single Walled Carbon Nanotubes
}

\author{
M. Abu-Abdeen \\ Physics Department \\ Faculty of Science \\ Cairo University \\ Giza, Egypt
}

\author{
A. I. Aboud \\ Physics Department \\ Faculty of Science \\ Cairo University \\ Giza, Egypt
}

\author{
G. H. Ramzy \\ Physics Department \\ Faculty of Science \\ Cairo University \\ Giza, Egypt
}

\begin{abstract}
Single walled carbon nanotubes (SWCNTs) were synthesized using alcohol catalyst chemical vapor deposition ACCVD method using ethanol and were characterized with TEM. The prepared SWCNTs were incorporated with different concentrations in Poly(vinyl chloride) with different concentrations. The effect of both SWCNTs concentrations and temperature on creep and creep recovery of PVC were studied. Burger's model was applied to the region of creep and material parameters like instantaneous elastic modulus, Voigt elastic modulus and viscosity, Newtonian viscosity and linear thermal expansion coefficient were calculated at different concentrations of SWCNTs and different temperatures. These parameters were found to have a maximum at $1 \mathrm{wt} \%$ of SWCNTs and also found to decrease with increasing temperature. The recovery relaxation time was calculated and the activation energy of chains upon heating was calculated and samples containing $5 \mathrm{wt} \%$ of SWCNTs was found to have a maximum of $0.36 \mathrm{eV}$.
\end{abstract}

Keywords: PVC, Carbon Nanotubes, Creep, Creep recovery

\section{INTRODUCTION}

Viscoelastic properties of materials are traditionally measured by uniaxial tests [1]. Creep, stress relaxation and dynamic loading tests are the commonly used techniques to measure the time-dependent analogs to elastic constants. The uniaxial creep test consists of measuring the time-dependent stretch resulting from the application of a steady axial load, and can be directly related to the viscoelastic properties. Viscoelasticity is an important characteristic of polymers. The long-term behavior of polymers is essential to estimate their life-time under load. Although creep in an anisotropic, multiphase system, like composites, is very complex, the analysis of creep properties is important for the use of composites in longterm applications. This may be more significant in reinforced polymer nano-composites than in classic materials reinforced by glass or basalt fiber. Polymer nano-composites have some advantages in addition to the good mechanical properties: easy and fully recyclability and low density [2 -7]. Relatively poor creep resistance of thermoplastic polymers is unfavorable to their application as structural materials. Creep deformation of polymers is easy to exceed the structural limitation, and fracture of ten occurs under long-term loading. To overcome the disadvantage, works were done started their attempts at the incorporation of nano - fillers. Rigid nan fillers used to improve mechanical performance of thermoplastic polymers have received considerable attentions in recent years [812].Strength, stiffness and toughness of nanocomposites can be simultaneously enhanced by improving dispersion of nanoparticles in polymer matrix as well as interfacial interaction between nanoparticles and matrix [13 -15]. Previous works [16 -18] showed that the glass transition temperature of polymers was increased by the incorporation of nanoparticles owing to a good bonding at the interface that restricts motion of the polymer chains. All of the above manifests that with the aid of inorganic nano fillers, performance of thermoplastics is becoming more attractive.
The one-dimensional structure of carbon nanotubes (CNTs), their low density, their high aspect ratio, and extraordinary mechanical properties make them particularly attractive as reinforcements in composite materials. By now, hundreds of publications have reported certain aspects of the mechanical enhancement of different polymer systems by CNTs [19-23]. The interest in the creation of nanocomposites based on the PVC matrix may be explained by an essential role played by this polymer. Poly (vinyl chloride) presents today an object of a manifold of applications, where its considerable environmental and chemical resistance, as well excellent mechanical properties may be cited. Therefore, the physical modification of the properties of this polymer, and specially the improvement of mechanical properties, was the based idea of this work.

In the present work the effect of both single walled carbon nanotubes content and temperature on creep and creep recovery behavior will be investigated. In this respect Burger's model will be used to study the viscoelastic creep behavior and material parameters like elastic moduli, coefficients of viscosity and relaxation times, linear thermal expansion coefficient will be deduced at different SWCNTs contents. Creep recovery behavior will be also investigated and both recovery relaxation time and activation energy will be calculated.

\section{Experimental}

\subsection{Materials and Preparation}

\section{1.a Polymer}

A commercial grade of Polyvinyl chloride (PVC) was supplied from Sabic Company, Saudi Arabia. It was in the powder form (powder fraction of 90-120 $\mu \mathrm{m}$, average size of $100 \mu \mathrm{m}$, density $\rho_{\mathrm{p}}=1.37 \mathrm{~g} / \mathrm{cm}^{3}$ ) was used as a polymeric matrix for preparation of composites. 


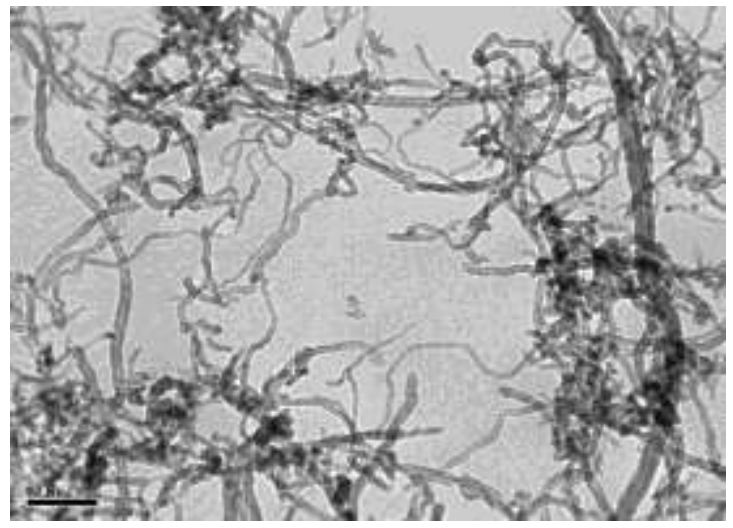

Fig. (1) Morphology of prepared CNT's as observed by TEM.

SWCNTs were grown via the alcohol catalytic chemical vapor deposition (ACCVD) technique using a $50 \mathrm{~cm}$ long ceramic tube furnace with diameter of $12 \mathrm{~cm}$. Cobalt acetate supported catalyst was first prepared as follows. A metal acetate solution was prepared by dissolving cobalt acetate $\left(\mathrm{CH}_{3} \mathrm{COOH}\right)_{2} \mathrm{Co}-$ $4 \mathrm{H}_{2} \mathrm{O}$ (99.999\%, Sigma-Aldrich) into ethanol (typically $42 \mathrm{mg}$ of cobalt acetate in $10 \mathrm{ml}$ of ethanol) so that the concentration of each metallic species was $0.01 \mathrm{wt} \%$ with stirring for $10 \mathrm{~min}$ followed by sonication for $2 \mathrm{~h}$ at room temperature. For a substrate, we employed n-type Si wafer with (100) surface polished at one surface (University Wafers, USA) and a thickness of $0.5 \mathrm{~mm}$. The substrate was cut into a strip of about $7 \times 20 \mathrm{~mm}^{2}$. The substrate was cleaned by consecutive acetone and methanol sonication for $5 \mathrm{~min}$, washed with DI water and blown with dry nitrogen. The substrate piece was then submerged vertically into the prepared metallic acetate solution for $5 \mathrm{~min}$. This piece was then drawn up from the solution at a constant speed of $4 \mathrm{~cm} / \mathrm{min}$. The surface of the substrate was rapidly dried at several millimeters above the liquid contact level as soon as it was removed from the solution. Right after this process, the piece was placed in a furnace and maintained at $400{ }^{\circ} \mathrm{C}$ for $5 \mathrm{~min}$ [24].

For the growth of SWCNTs, Cobalt acetate supported catalyst was placed into alumina combustion boat; whereas a $10^{\circ}$ inclined graphite stage was used to support the substrates and the group was then placed at the center of the tube furnace. The tube was evacuated to $150 \mathrm{mTorr}$, and samples were heated to the desired reaction temperature under $250 \mathrm{sccm}$ of flowing argon. Once the growth temperature was reached (depending on the growth temperature), samples were held at that temperature for $5 \mathrm{~min}$. The argon was then shut off and the tube was evacuated before the introduction of alcohol vapor. The alcohol vapor (ethanol) was then transferred into the tube furnace to achieve a pressure of 5-10 Torr. The alcohol flow rate in the growth chamber was controlled by controlling the alcohol bath temperature. After growth, the alcohol vapor was evacuated, argon was introduced again and the reaction tube was cooled to room temperature. SWCNTs growth time was kept constant at 50min unless otherwise stated [25].

Nanotubes grown in powder form were sonicated in methanol and placed onto holey/lacey carbon coated copper grids for TEM (Model 1011 JEM at $100 \mathrm{KV}$ KSU, Saudi Arabia) observations to confirm both their existence and morphology and shown in Figure 1.

\section{1.c Preparation of the Polymer composite}

PVC was dissolved in tetrahydrofuran (THF) by slowly mixing for $24 \mathrm{hr}$. SWCNTs was added to the PVC solution to get composites from SWCNTs/PVC with different weight percent (Typically, 0, 0.25, 0.35, 0.5, 0.88, 1, 1.5, 2, 2.5 and 5 wt \%). The solution will be prepared in a dark laboratory bottle, by slowly mixing during $24 \mathrm{~h}$ at an ambient temperature. The composites of PVC with SWCNTs with different concentrations were prepared in the form of thin sheets cast from PVC solution in THF. Parts of the composites solution were spin coated on Si substrates for AFM imaging. The aim of a multi-step procedure used to prepare the PVC loaded SWCNTs nano composites was done to achieve the distribution of the carbon nanotubes in nano composites as homogeneous as possible. In the first step the SWCNTs was dispersed in the PVC solution using a combined procedure; quick mixing and ultrasonication at room temperature during $5 \mathrm{~min}$., alternatively three times every procedure. The second step was the preparation of thin films with thickness of $0.1 \mathrm{~mm}$ cast from the nanocomposite solution in THF on a glass surface with controlled horizontal position.

\subsection{Creep tests}

The creep and creep recovery tests were carried out using TA instruments DMAQ800 machine (USA), using the tension film clamping arrangement. Specimens in the form of sheets with dimensions $9 \mathrm{~mm}$ length, $4 \mathrm{~mm}$ width and $0.1 \mathrm{~mm}$ thick were used. Temperature was automatically controlled and samples were left isothermally for $5 \mathrm{~min}$. at $25,30,35,40$ or $45^{\circ} \mathrm{C}$ before testing. The sensitivity in temperature during testing was in the range $\pm 0.2{ }^{\circ} \mathrm{C}$. A stress of $20 \mathrm{MPa}$ was suddenly applied after a constant temperature was established. The strain produced in the specimen was recorded with time for $15 \mathrm{~min}$. After that, stress was removed suddenly and the recovery strain was also collected with time for $20 \mathrm{~min}$.

\section{Results}

Among physical models for creep [26-28], the strain response $\varepsilon(t)$ of a polymer to the applied stress $\sigma$ can be represented by three parts: (1) elastic or instantaneous deformation, (2) visco-elastic deformation and (3) viscous deformation. These can be represented schematically as in figure (2) and mathematically by:

$$
\varepsilon(t)=\varepsilon_{\text {elastic }}(t)+\varepsilon_{\text {visco-elastic }}(t)+\varepsilon_{\text {creep }}(t)
$$

Or

$$
\varepsilon(t)=\frac{\sigma}{E_{1}}+\frac{\sigma}{E_{2}}\left[1-\exp \left(-t \frac{E_{2}}{\eta_{2}}\right)\right]+\frac{\sigma}{\eta_{1}} t
$$

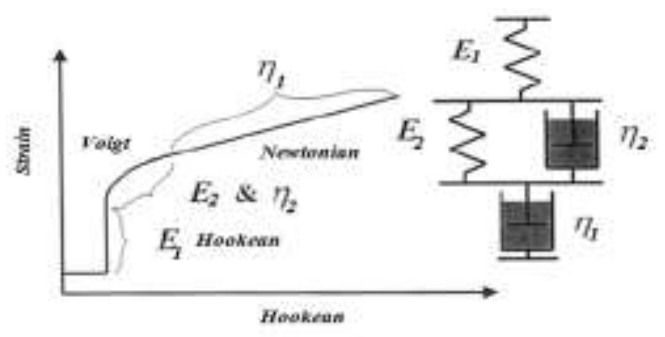

Fig (2) Quantitative Analysis of the creep curve. 


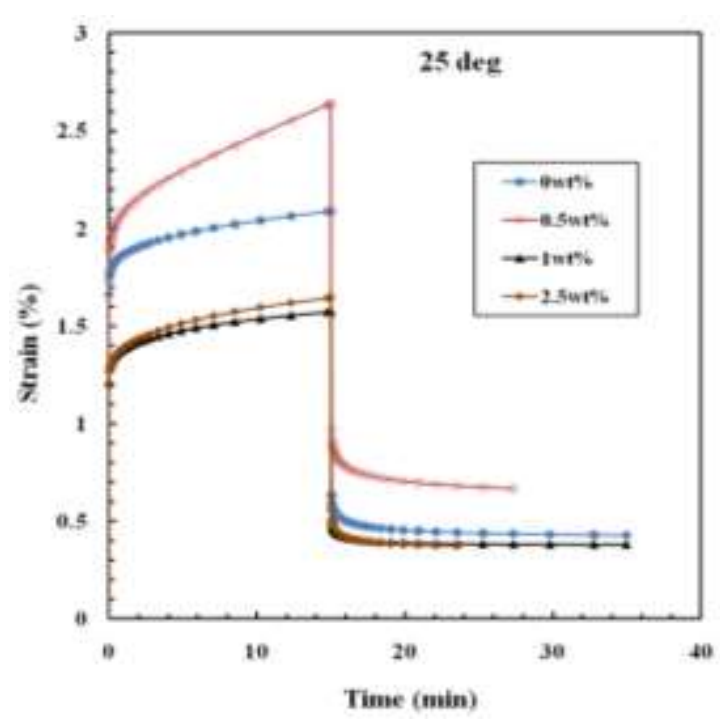

Fig. (3) Creep curves for MWCNT's loaded samples at 25 C.

where $\varepsilon(t)$ is the creep strain, $\sigma$ is the applied stress, $t$ is time, $E_{1}$ and $E_{2}$ are the elastic moduli of the Maxwell and the Voigt springs, and $\eta_{1}$ and $\eta_{2}$ are viscosities of the Newtonian and the Voigt dashpots.

In equation (2), the first term is the instantaneous creep strain, which can result from changes in bond lengths and angles, for instance. The second term is the early stage creep strain and is due to mechanisms such as molecular chain relaxations and extensions. The last term is the long-term creep strain and is due to viscous slippage of molecular chains, for instance.

Since polymers are viscoelastic materials that have combined mechanical properties of elastic solids and viscous fluids, they respond to an external force in a manner intermediate between the behavior of an elastic solid and a viscous fluid [29,30]. Burger's model provides a mechanism to gain insight into this behavior. The DMA creep-recovery curve for PVC loaded with different concentrations of SWCNTs resembles the response predicted by Burger's model, suggesting that the macroscopic viscoelasticity of the polymer may be understood in terms of this model. The large time-independent, virtually instantaneous strain upon the impulsive increase of the stress indicates elastomeric behavior with a weak Hookean constant.

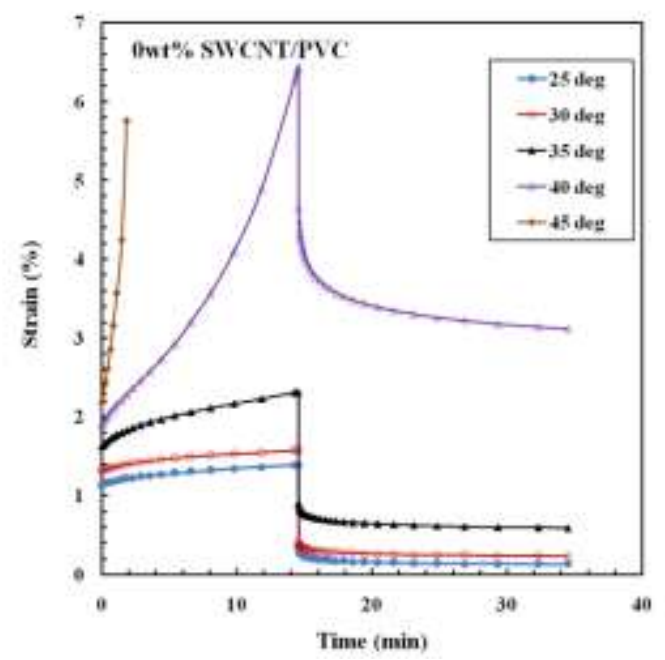

Fig. (4) Creep curves for unloaded samples at different temperatures.

$\underline{\text { www.ijsea.com }}$

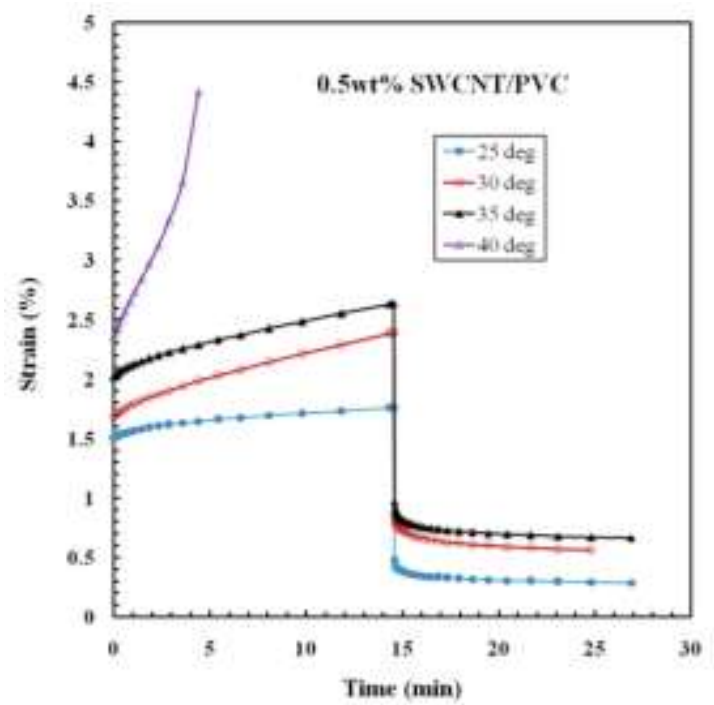

Fig. (5) Creep curves for samples loaded with 0.5 wt\% SWCNT's at different temperatures.

The weaker the Hookean constant, the larger the initial fast displacement. After the weak Hookean spring reaches its maximum displacement, the polymer slowly shifts through the curvature of the Voigt region to the Newtonian region.

The creep response is time-dependent and indicates the yielding of the polymer to the stress by reorganization of its internal microscopic structure. The creep rate of SWCNT/PVC is indicative of the stability of its elastomer structure. When, after $15 \mathrm{~min}$ of constant stress, the stress is suddenly reduced back to $0.05 \mathrm{~N}$, the polymer is able to recover from almost half of its maximum elongation. This is consistent with moderate elastomeric stability.

Figure (3) shows the creep and creep recovery for all studied samples at a temperature of $25^{\circ} \mathrm{C}$ and applied stress of $20 \mathrm{MPa}$. Sample loaded with $1 \mathrm{wt} \%$ of SWCNTs possesses minimum instantaneous strain and steady strain rate. Creep and creep recovery experiments at temperatures $25,30,35,40$ and $45^{\circ} \mathrm{C}$ for PVC samples loaded with 0, 0.5, 1.0, 2.5 and $5.0 \mathrm{wt} \%$ of SWCNTs under constant stress of $20 \mathrm{MPa}$ are shown in Figures $(3-7)$ respectively.

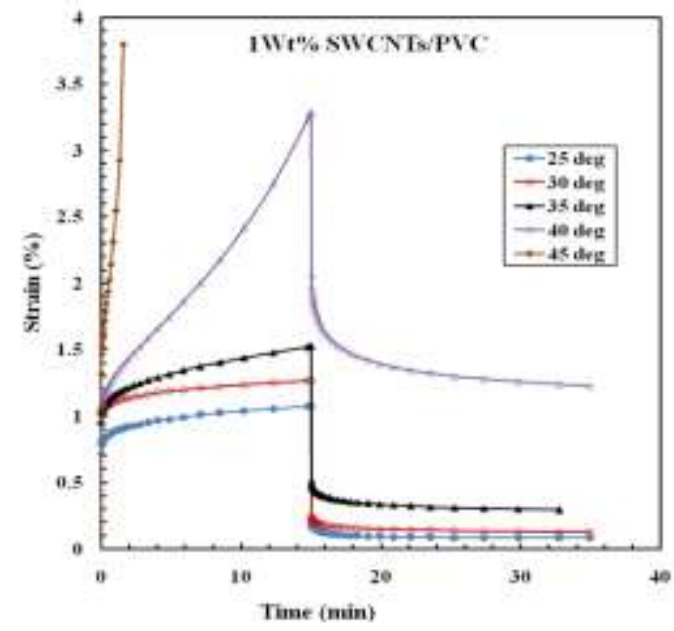

Fig. (6) Creep curves for samples loaded with 1 wt $\%$ SWCNT's at different temperatures. 


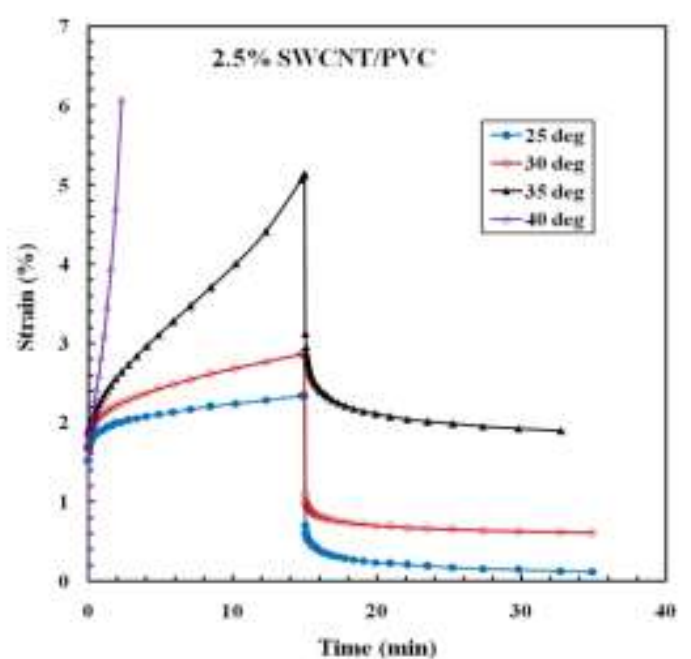

Fig. (7) Creep curves for samples loaded with 2.5 wt\% SWCNT's at different temperatures.

\subsection{Instantaneous deformation}

The instantaneous strain as the stress was applied is found to increase linearly with temperature, as shown in Figure (8), according to the equation

$$
\varepsilon_{o}=\varepsilon_{o}^{\prime}+\alpha T
$$

where $\varepsilon_{o}^{\prime}$ is a constant indicating the strain at zero Kelvin and $\alpha$ is the slope of the lines. From the definition of the strain ( $=\Delta L / L_{o}$ ), the constant $\alpha$ may indicates the coefficient of linear expansion, under a constant tensile stress of $20 \mathrm{MPa}$, of the studied composites and its values are listed in table (1). The values of $\alpha$, in general, decrease with increasing the weight content of SWCNTs as a result of originally high values of $\alpha$ of PVC over SWCNTs.

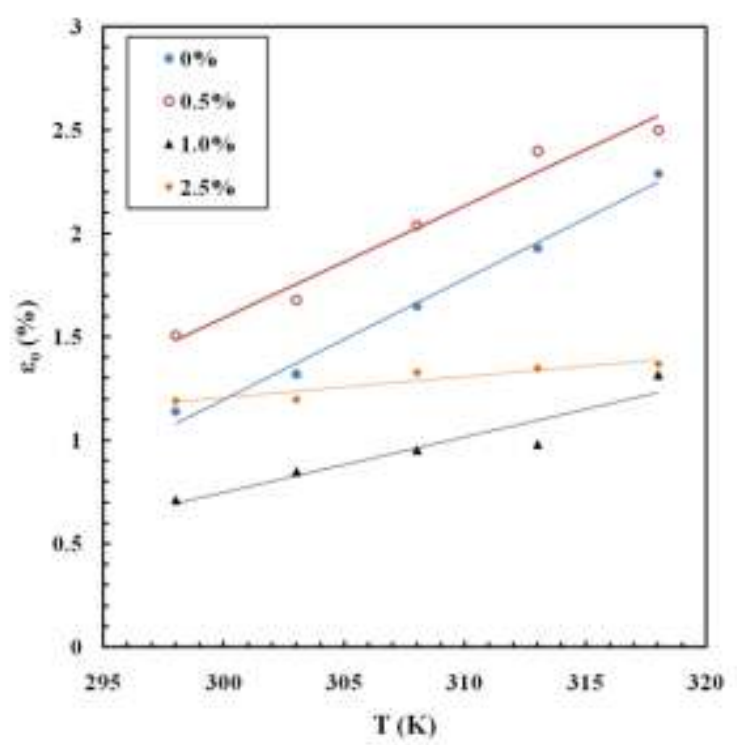

Fig. (8) The instantaneous strain versus temperature for MWCNT's loaded samples

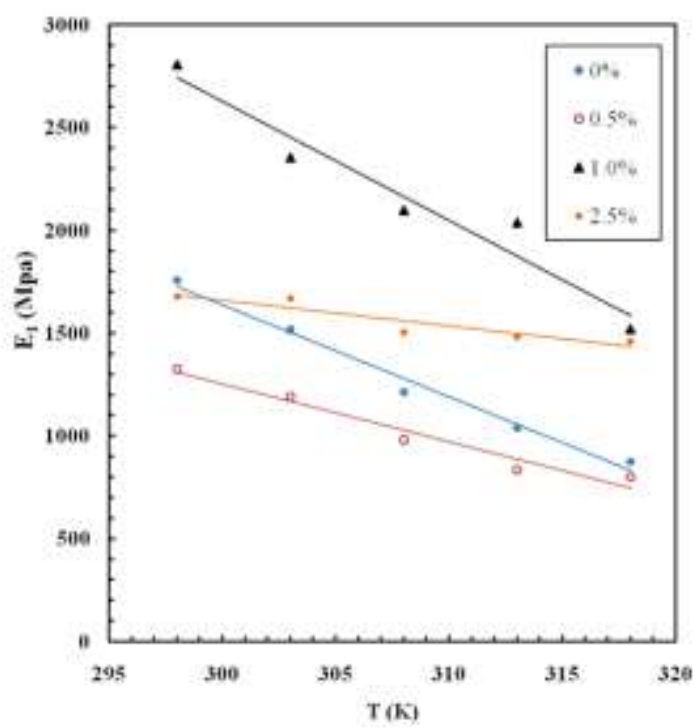

Fig. (9) The tensile elastic modulus $E_{1}$ versus temperature for all composites

The tensile elastic modulus $E_{1}$ of Maxwell springs and its dependence on temperature for all the studied composites is calculated using the first term in equation (2). The calculated data are illustrated in figure (9) and found to obey a straight line equation of the form

$$
E_{1}=E_{1 o}-A T
$$

where $E_{1 o}$ is elastic modulus of Maxwell springs at zero Kelvin. The constant $A$ represents the slopes of the lines with values listed in table (1). This constant may represent the energy density acquired by the material when the temperature increased by one degree. Samples containing 1 wt $\%$ of SWCNTs have maximum values of $A$ which agree very well with the values of Young's modulus achieved in a previous work for these composites [29].

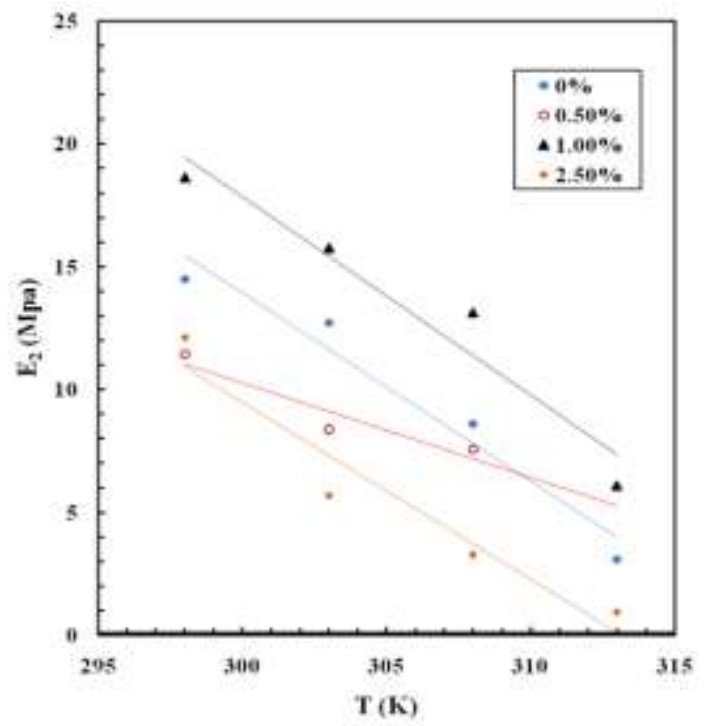

Fig. (10) The tensile elastic modulus $E_{2}$ versus temperature for all composites 
Table (1)

\begin{tabular}{|c|c|c|c|c|c|}
\hline $\begin{array}{l}\text { Wt \% of } \\
\text { SWCNTs }\end{array}$ & $\alpha \times 10^{-4}\left(\operatorname{deg}^{-1}\right)$ & $\begin{array}{c}A \times 10^{6} \\
\mathrm{~J} / \mathrm{m}^{3} . \mathrm{deg}\end{array}$ & $\begin{array}{l}A^{\prime} \text { for } E_{2} \\
J / m^{3} \text {.deg }\end{array}$ & $\begin{array}{l}\mathbf{A}^{\prime} \text { for } \eta_{2} \\
\text { Pa.s/deg }\end{array}$ & $\begin{array}{c}E_{\mathbf{r}} \\
(\mathbf{e V})\end{array}$ \\
\hline 0 & $5.80-59.1$ & 44.8 & 0.77 & 0.3 & 0.054941 \\
\hline 0.5 & $5.40-70$ & 28.1 & 0.39 & 1.1 & 0.185006 \\
\hline 1.0 & $2.60-60$ & 57.8 & 0.81 & 4.32 & 0.231495 \\
\hline 2.5 & $0.90-50$ & 6.74 & 0.46 & 1.06 & 0.50922 \\
\hline 5 & $1.00-46$ & 12.5 & 0.72 & 0.82 & 0.435218 \\
\hline
\end{tabular}

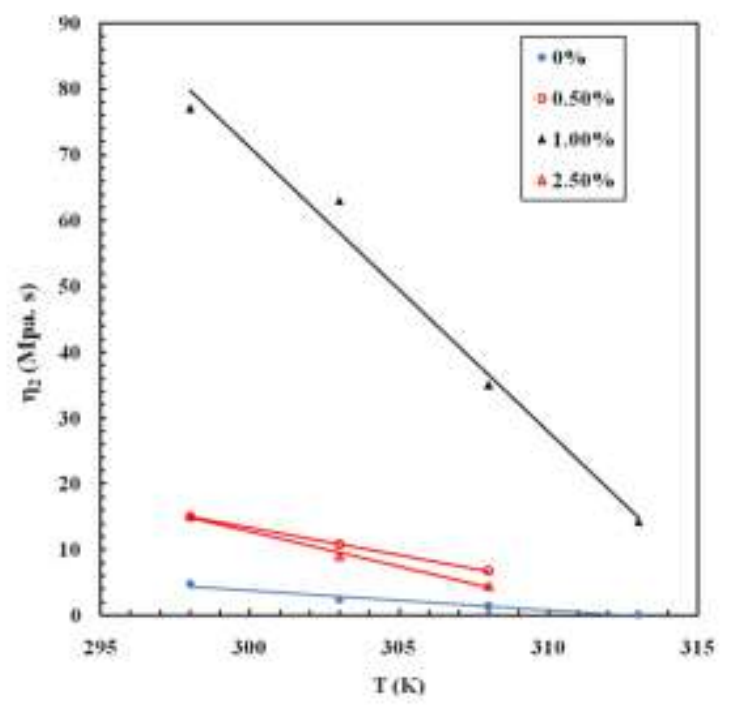

Fig. (11) The viscosity coefficient $\eta_{2}$ versus temperature for all composites

\subsection{Visco-elastic deformation}

As the stress is suddenly applied to the material, all the deformations take place instantaneously in the Hookean spring. As time goes, these deformations transfer gradually to the Voigt and dashpot describing Newtonian deformation. Both the elastic modulus $E_{2}$ and the coefficient of viscosity $\eta_{2}$ of the spring and dashpot of Voigt unit are calculated according to equation (2) at different concentrations of SWCNTs as well as temperature. These results are shown in Figures 10 and 11.Both $E_{2}$ and $\eta_{2}$ decrease linearly with increasing temperature and each of them obeys a linear function of the form:

$$
\Psi_{2}(T)=\Psi_{o 2}-A^{\prime} T
$$

where $\Psi_{2}(T)$ represents either $E_{2}$ or $\eta_{2}$ at temperature $T, \Psi_{o 2}$ is the value of either $E_{2}$ or $\eta_{2}$ at zero Kelvin. When $\Psi_{2}(T)$ describes $E_{2}$ the constant $A^{\prime}$ has the same meaning as described in equation (4) and their values are shown in table (1). As described in section 3.1, $E_{2}$ has maximum value at $1 \mathrm{wt} \%$ loading of SWCNTs. In the case of either $A$ or $A^{\prime}$ when dealing with Hookean or Voigt springs, the reason behind their maxima at $1 \mathrm{wt} \%$ of SWCNTs may be due to the folding of Polymer chains around the length of the CNTs making additional entanglements which results in strengthen the composite. Besides, this may be due to direct bonding between chain ends and CNTs [30]. Concentrations of SWCNTs more or less than $1 \mathrm{wt} \%$, may produce agglomerations which results in a less folding of polymer chains as well as less bonding between www.ijsea.com chain endings and SWCNTs. On the other hand, when $\Psi_{2}(T)$ describes $E_{2}$ the slope $A^{\prime}$ represents the change in viscosity of the Voigt dashpot at different concentrations of SWCNTs and its values are presented in table 1 . The change in viscosity of the dashpot 2 has a maximum at $1 \mathrm{wt} \%$ of SWCNTs loading.

\subsection{Viscous deformation}

The last deformation in the creep experiments is the Newtonian viscous flow which represented by a dashpot 1 . The viscosity of this dashpot is changed with temperature as well as the concentration of SWCNTs as shown in Figure 12. Maximum coefficient of viscosity is found for $1 \mathrm{wt} \%$ of SWCNTs and low temperature of $25{ }^{\circ} \mathrm{C}$. Heating the material produces energy gained by polymer chains which can reorient themselves easily and this result as a decrease in the coefficients of viscosity of both dashpots. Thus we can say that both dashpots relax to their new positions under an external stress faster at higher temperatures. These relaxations are associated with characteristic times called relaxation times which related to the coefficients of viscosity according to:

$$
\tau_{1}=\frac{\eta_{1}}{\sigma}, \quad \tau_{2}=\frac{\eta_{2}}{E_{2}}
$$

Both relaxation times are calculated for all studied composites at different temperatures and shown in figures 13 and 14 and it was noted a decrease in both with temperature but with higher values of $\tau_{1}$ over $\tau_{2}$ at same temperature and SWCNTs loading.

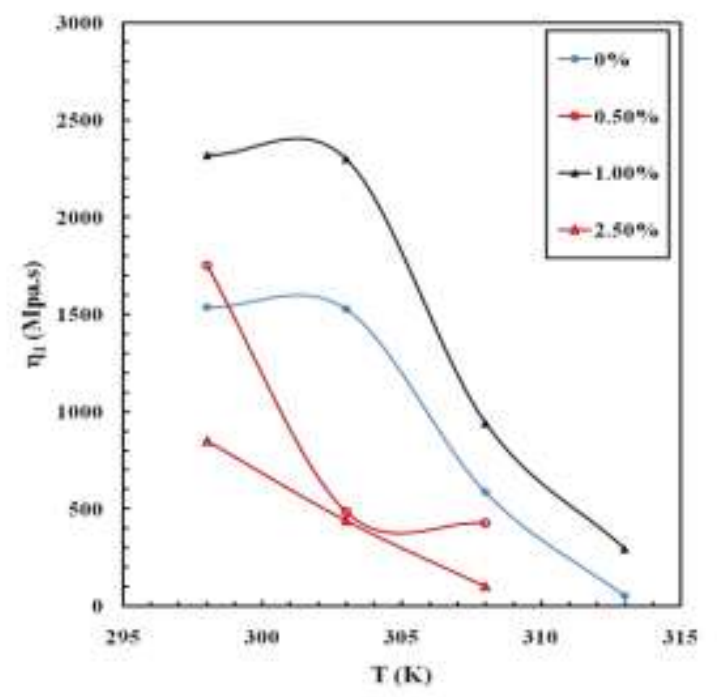

Fig. (12) The viscosity coefficient $\eta_{I}$ versus temperature for all composites 


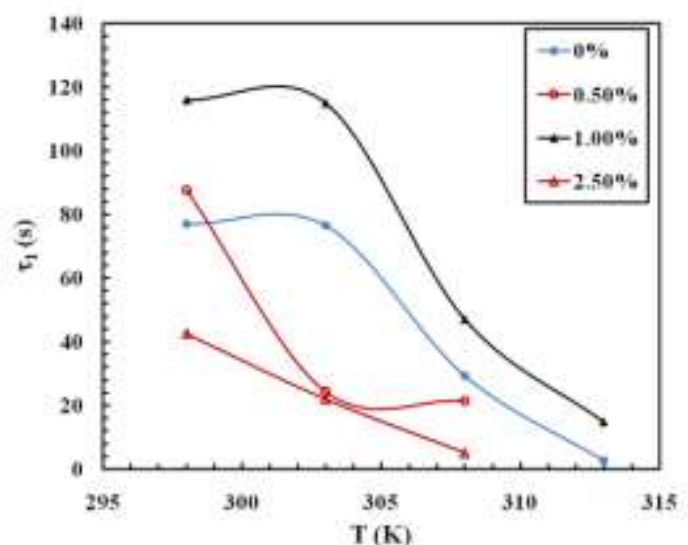

Fig. (13) The relaxation time $\tau_{1}$ versus temperature for MWCNT's loaded sample

\subsection{Creep recovery}

In order to study the creep recovery of a test sample, after the steady creep rate was attained, the stress was suddenly removed from and the strain was continuously recorded versus time, an instantaneous strain recovery took place followed by a gradual decrease in the sample's strain which finally reached an asymptotic value. Figures $(3-7)$ represent sets of tensile creep and creep recovery curves under different conditions of SWCNTs loading and temperature. In the following analysis the term tensile creep recovery, $\varepsilon_{r}$ will be assigned to the recoverable strain after time $t$ from removal of stress. It is calculated by the difference between the observed strain at time $t$ after unloading and the asymptotic strain attained after infinite time. The recoverable strain is here assumed to decrease with time according to an exponential decay function of the type

$$
\varepsilon_{r}=\varepsilon_{r o} \exp \left(-\frac{t}{\tau_{r}}\right)
$$

where $\varepsilon_{r o}$ and $\tau_{r}$ are constants. This assumption proved to be valid for the initial parts of the recovery curves on account of the straight line relations between $\log \varepsilon$ r versus $t$, shown in figures 15 and 16 for samples containing 0 and $1 \mathrm{wt} \%$ of SWCNTs. The rest of figures describing other composites are not mentioned to avoid repetition. The constant $\tau_{r}$ in equation (7), which is the reciprocal of the slopes of the lines in figures 15 and 16, might be given its usual physical meaning of recovery relaxation time characterizing creep recovery. It was

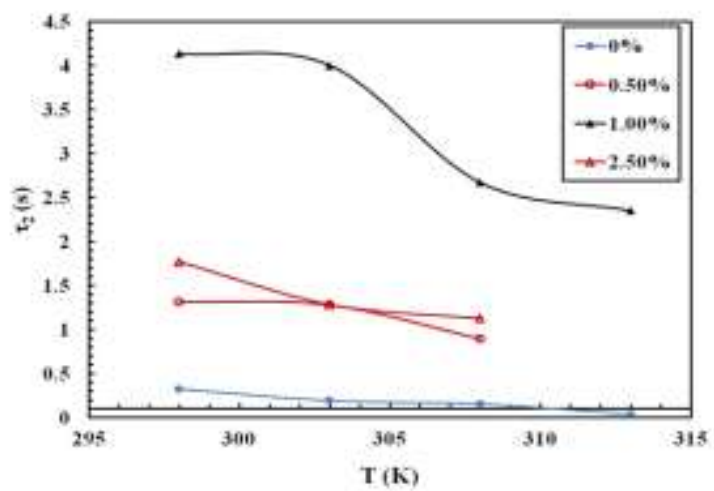

Fig. (14) Fig. (13) The relaxation time $\tau_{2}$ versus temperature for MWCNT's loaded sample

$\underline{\text { www.ijsea.com }}$

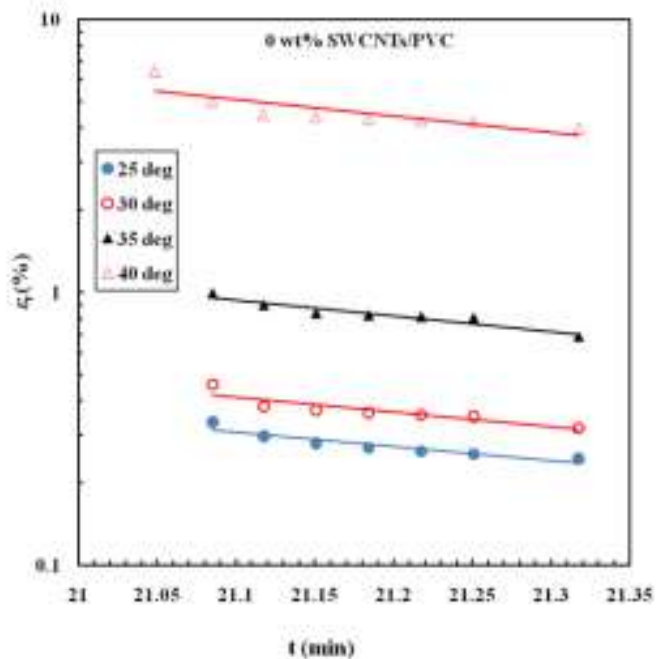

Fig. (15) The recoverable strain as a function of time at different temperatures for $0 \mathrm{wt} \%$ MWCNT's loaded samples.

presently calculated in every case tested and the values obtained are given in the figure 17.

The energy of creep recovery of the samples could be determined from the observed temperature dependence of the recovery relaxation time $\tau_{r}$ which time might be written in the form

$$
\tau_{r}=\tau_{r o} \exp \left(\frac{E_{r}}{k T}\right)
$$

where $T$ is the absolute temperature, $k$ is the Boltzmann constant and $E_{r}$ is the activation energy of the relaxation process characterizing creep recovery.

A plot of the logarithm of the relaxation time $\tau_{r}$ versus $1 / T$ yielded straight lines for all studied composites as shown in figure 17 . The activation energy characterizing the relaxation process responsible for creep recovery is presented in table (1). The activation energy is increased from 0.071 to 0.37 when the weight percentage of SWCNTs increased from 0 to $5 \mathrm{wt} \%$, respectively.

\section{Discussion of the results}

The values of $E_{1}$ and $E_{2}$ correspond to the modulus in the Hookean and Voigt regions of the creep response, respectively. The general magnitude of these parameters is an indicator of strength, with larger values corresponding to smaller strain orientations reached for a given amount of stress. In Figure 9 the Hookean $E_{l}$ values differentiate the bands from the hard and soft segments, with the hard segments generally possessing higher modulus values. This observation indicates that, during the initial stage of the impulse time-independent elastic deformation, the soft domains orient more, contributing more to the macroscopic deformation, while the hard domains orient less, contributing more to the elasticity or Young's modulus (initial strength). The trend observed for $E_{2}$ (Voigt region) is similar to that observed for $E_{1}$.

The analysis of the parameter $\eta_{1}$ provides insights into the slow structural rearrangement of the polymer morphology after it is already stressed and deformed. The polymer then has mobility to deform, and even after it has been strained several times its original length, the network structure is not 


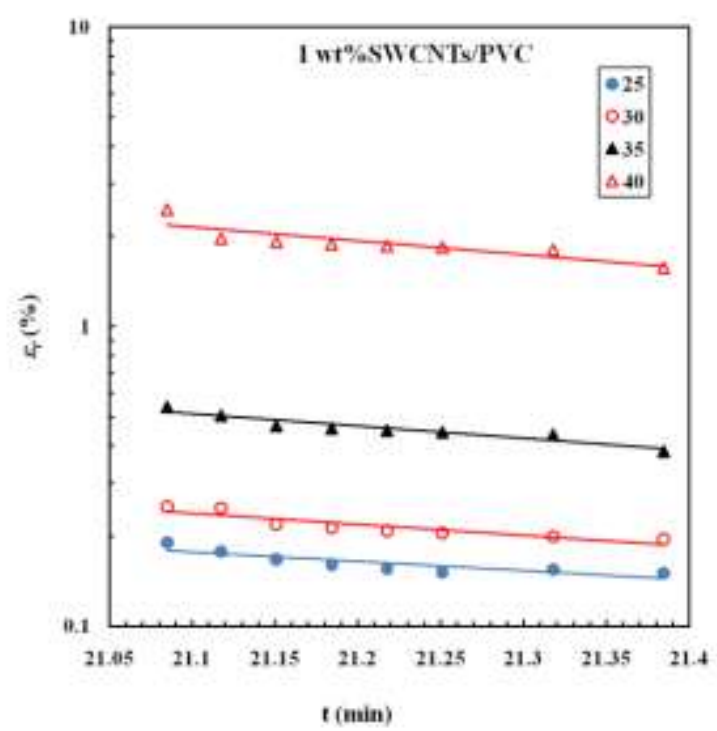

Fig. (16) The recoverable strain as a function of time at different temperatures for $1 \mathrm{wt} \%$ MWCNT's loaded samples.

significantly changed. As a result, upon the release of the stress, the polymer is able to recover to nearly its original length. While the Hookean (initial) region provides insights into the mobility of the morphological structure, the Newtonian region provides insights into the stability of the network structure. The slow change in this region is characteristic of the motion of a highly viscous material that undergoes slow but steady irreversible changes.

The decrease in $E_{1}$ and $E_{2}$ resulted from the increases in the instantaneous and the viscoelastic deformations as temperature increased. The decreases in $\eta_{1}$ and $\eta_{2}$ suggest an improvement in the mobility of molecular chains at higher temperature. The parameters for SWCNTs/PVC experienced the largest decreasing change, especially those containing 1 wt $\%$. Also, $\eta_{1}$, which is related to the long-term creep rate, has more decreasing change over $\eta_{2}$ and demonstrates the large temperature-dependence of this composite. The observed creep relaxation in SWCNTs/PVC is thought to have its origin at the restoration motion of molecular segments after the removal of stress.

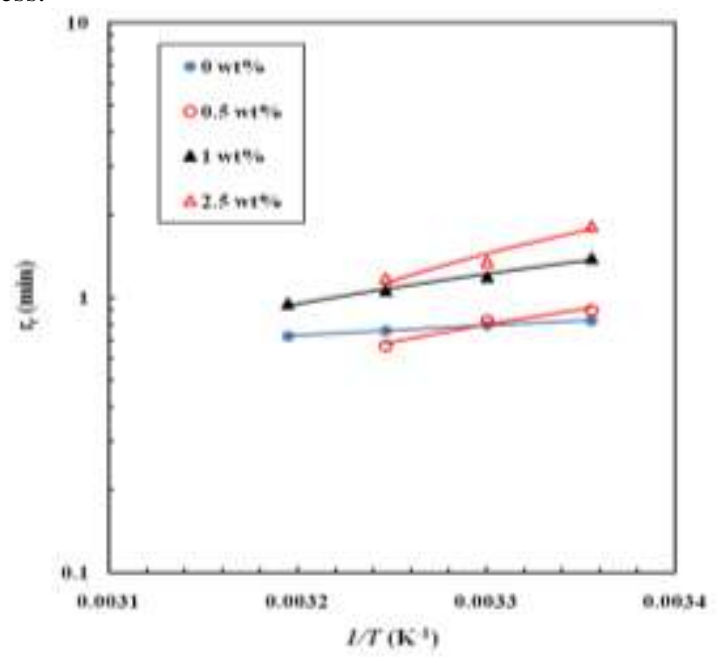

Fig. (17) The recovery relaxation time versus the reciprocal of temperature for MWCNT's loaded samples

$\underline{\text { www.ijsea.com }}$
Translational or rotational motion of macromolecular segments in a polymer is usually enhanced by thermal energy or by the action of an externally applied field of force. However, this motion is usually opposed by intermolecular forces responsible for the cohesion of the molecular aggregates. The flexibility of the molecular chain under the action of an externally applied stress depends on the ease with which the different structural elements along the chain can displace or rotate to contribute to the elastic strain. The observed energy of activating of the present relaxation mechanism is thought to describe the average height of the potential barrier created by the cohesive forces between the structural segments along and between the neighboring chains. The addition of SWCNTs increases these cohesive forces and thus increases the average height of potential barriers resulting as increase in the activation energy.

\section{Conclusions}

This work reports a discrete temperature-dependent creep and creep recovery spectra at different concentrations of SWCNTs, which may be used to describe the mechanical response of nonlinear viscoelastic polymers. This work supports the following specific conclusions.

1. Study of the mechanical properties of the PVC/CNTs and $\mathrm{PVC} / \mathrm{CNP}$ composites depending on the content of nanofillers demonstrate an increase in Young's modulus by 3 times at concentration of $1 \mathrm{wt} \%$ of CNTs and 1.4 times at $2 \mathrm{wt} \%$ of CNP. The change in micro-hardness degree is also increased by 3.5 and 2.5 times at same concentrations. The tensile strength, strain at break decrease with increasing either nanofiller.

2. The presence of nanofillers reduces the percolation threshold from $1 \mathrm{wt} \% \mathrm{CNP}$ to $0.5 \mathrm{wt} \%$ CNTs. It is caused by high anisotropy of the CNTs and CNP and the presence of a segregated structure of them within the polymer matrix with distribution of nanofillers on the boundaries between the polymer grains.

3. Composites containing CNTs can be better employed for electronic and microwave devices working at different temperatures since their electrical conductivity is independent from temperature in the studied range.

4. Concentrations of either nanofiller in the percolation region produce a jump region in the $\mathrm{I}-\mathrm{V}$ curve. The conduction mechanism is Ohmic for other composites.

\section{References}

[1] Mohan R, Adams D F, Nonlinear creep-recovery response of a polymer matrix and its composites, Exp Mech, Sept, 1985, 262.

[2] Giles JM, Black AE, Bischoff JE. Anomalous rate dependence of the preconditioned response of soft tissue during load controlled deformation. J Biomech 2007; 40(4):777-785.

[3] Haj-Ali RM, Muliana AH. Numerical finite element formulation of the Schapery's nonlinear viscoelastic material model. Int J Numer Methods Eng 2004; 59: $25-$ 45. 
[4] Zaoutsosa SP, Papanicolaou GC, On the influence of preloading in the nonlinear viscoelastic-viscoplastic response of carbon-epoxy composites Comp Sci and Tech, 70, 2010, 922-929.

[5] Varela-Rizo H, Weisenberger M, Bortz, DR, MartinGullon I, Fracture toughness and creep performance of PMMA composites containing micro and nanosized carbon filaments , Compos Sci. and Tech. Article in Press.

[6] Li, J., Ngan, A.H.W, Nanoscale fast relaxation events in polyethylene , Scripta Materialia 62 , 2010, (7), pp. 488491

[7] Jia M, Xue P, Zhao Y, Wang K, Creep behavior of wood flour/poly(vinyl chloride) composites, Journal Wuhan University of Technology, Materials Science Edition 24, 2009, (3), pp. 440-447

[8] Amy, Y.-H.L., Jörg R, Physical aging and structural relaxation in polymer nanocomposites, Journal of Polymer Science, Part B: Polymer Physics 47,2009, (18), pp. $1789-1798$

[9] Zhou, TH, Ruan WH, Yang, JL, Rong MZ, Zhang MQ, Zhang Z, A novel route for improving creep resistance of polymers using nanoparticles, Comp Sci Tech 67, 2007, (11-12), pp. 2297-2302

[10] Xia H, Song M, Zhang Z, Richardson M, Microphase separation, stress relaxation, and creep behavior of polyurethane nanocomposites, J of Appl Polym Sci 103, 2007, (5), pp. 2992-3002

[11] Devasenapathi V, Monish P, BalasivanandhaPrabu S, Experimental investigation of tensile creep behavior of polymer nanocomposites, International Journal of $A d v$ Man Tech 44, 2009 (3-4), pp. 412-418

[12] Muenstedt H, Katsikis N, Kaschta J, Rheological properties of poly(methyl methacrylate)/nanoclay composites as investigated by creep recovery in shear , Macromol 41, 2008, (24), pp. 9777-9783

[13] Rong MZ, Zhang MQ, Zheng YX, Zeng HM, Walter R, Friedrich K. Structure-property relationships of irradiation grafted nano-inorganic particle-filled polypropylene composites. Polym 2001; 42:167-83.

[14] Zhang MQ, Rong MZ, Zeng HM, Schmitt S, Wetzel B, Friedrich K. Atomic force microscopy study on structure and properties of irradiation grafted silica particles in polypropylene-based nanocomposites. $J$ Appl Polym Sci 2001; 80: 2218-2227.

[15] Ruan WH, Zhang MQ, Rong MZ, Friedrich K Polypropylene composites filled with in situ grafting polymerization modified nanosilica particles. J Mater Sci 2004; 39:3475-8.

[16] Ruan WH, Zhang MQ, Rong MZ, Friedrich K. Polypropylene composites filled with in situ grafting polymerization modified nanosilica particles. $J$ Mater Sci 2004; 39: 3475-8.
[17] Zhang YQ, Lee JH, Rhee JM, Rhee KY. Polypropyleneclay nanocomposites prepared by in situ graftingintercalating in melt. Compos Sci Technol 2004; 64:1383-9.

[18] Abu-Abdeen M. Investigation of the rheological, dynamic mechanical, and tensile properties of single-walled carbon nanotubes reinforced poly (vinyl chloride). J Appl Polym Sci 2012;124: 3192-9.

[19] Coleman JN, Khan U, Blau WJ, Gun'ko YK. A reviewof the mechanical properties of carbon nanotube polymer composites. Carbon 2006; 44:1624-52.

[20] Moniruzzaman M, Winey KI. Polymer nanocomposites containing carbon nanotubes. Macromolecules 2006; 39:5194-205.

[21] Miyagawa H, Misra M, Mohanty AK. Mechanical properties of carbon nanotubes and their polymer nanocomposites. J Nanosci Nano technol 2005; 5:1593615.

[22] Salvetat JP, Bhattacharyya S, Byron Pipes R. Progress on mechanics of carbon nanotubes and derived materials. $J$ Nanosci Nano technol 2006; 6: 1857-82.

[23] Tjong SC. Structural and mechanical properties of polymer nanocomposites. Mater Sci Eng R 2006;53:73197.

[24] Murakami Y, Miyauchi Y, Chiashi S, Maruyama S, Direct synthesis of high-quality single-walled carbon nanotubes on silicon and quartz substrates, Chem Phys Lett, 2003, $377,49-54$.

[25] Unalan HE, Chhowalla M, Investigation of single-walled carbon nanotube growth parameters using alcohol catalytic chemical vapor deposition, Nanotech, 2005, 16, 2153-2163.

[26] Acha BA, Reboredo MM, Marcovich NE, Creep and dynamic mechanical behavior of PP-jute composites: effect of the interfacial adhesion. Composites, Part aAppl Sci Man 2007, 38, 1507-1516.

[27] Nunez AJ, Marcovich NE, Aranguren MI, 2004. Analysis of the creep behavior of polypropylene-wood flour composites. Polym Eng Sci, 2004, 44, 1594-1603.

[28] Marcovich NE, Villar MA, 2003. Thermal and mechanical characterization of linear low density polyethylene/wood flour composites. J Appl Polym Sci, 2003, 90, 27752784 .

[29] Elias, H. Macromolecules, 2nd ed.; Plenum Press: New York,1984.

[30] Aklonis, J. J.; MacKnight, W. J. Introduction to Polymer Viscoelasticity; John Wiley \& Sons: New York, 1983.

[31] Coleman J N, Khan U, Gun'ko Y K, Mechanical reinforcement of polymers using carbon nanotubes, $A d v$ Mater 2006, 18, 689-706. 